\title{
Classification of Aphasic Phenomena
}

\author{
ANDREW KERTESZ
}

SUMMARY: A brief but comprehensive survey of classifying aphasia reveals that most investigators describe at least four major groups, conveniently labelled Broca's, Wernicke's, anomic and global. Conduction and transcortical aphasias are less generally described and modality specific syndromes rarely, if ever, exist purely. The controversy between anifiers and splitters continues bat objective numerical taxonomy may solve some of the problems of classification.

RÉSUME: Une étude brève, mais compréhensive, de la classification de l'aphasie révèle que la plupart des chercheurs décrivent au moins 4 groupes majeurs, clairement identifiés: Broca, Wernicke, anomique et globale. Les aphasies de condaction et transcorticales sont décrites de façon moins générale et les syndromes modaux spécifique ne se retrouvent que rarement, sinon jamais sous forme pure. La controverse de classification continue mais la taxonomie numérique objective peut aider à résoudre quelques-uns des problèmes courants.
From the Department of Clinical Neurological Sciences, St. Joseph's Hospital, London, Canada.

Reprint Requests to: Dr. Andrew Kertesz, Department of Clinical Neurological Sciences, St. Joseph's Hospital, London, Ontario, Canada N6A $4 \mathrm{~V} 2$
Most clinicians will agree that although aphasic disability is complex, many patients are clinically similar and may be classified into identifiable groups. There are many. classifications indicating that none is altogether satisfactory. Nevertheless, this effort is useful and even necessary to diagnose and treat aphasics and to understand the phenomena. The opponents of classification point out the numerous disagreements among observers, the many exceptions that cannot be fitted into categories and the frequent evolution of certain types into others.

The controversy can be reduced to a few issues. Is aphasia a unitary disturbance or are there several kinds of aphasia? The answer, of course, is yes to both. There is something qualitatively different about aphasic language disturbance which sets it apart from dysarthria, mutism, confusion and psychotic speech, just to mention the main problems in differential diagnosis. What makes it qualitatively different is difficult to define to everyone's satisfaction, but, the following definition might be acceptable to most: A neurologically central disturbance of language characterized by paraphasias, word finding difficulty and variably impaired comprehension, associated with a disturbance of reading and writing with or without dysarthria, non-verbal constructional and problem-solving difficulty and impairment of gesturing (constructional and motor apraxia).

Ever since Broca (1861) described "aphemia" and Wernicke (1874), sensory aphasia, many clinicians have tried to record their experience and improve the results of classification. Although confusing at first glance, after gaining some clinical experience, one finds it striking that the new classifications and descrip- tions cover the same phenomenon. In Table I the various terms are shown to overlap and those describing the same disturbance appear underneath each other. Four columns appear to represent the entities that almost everybody identifies:

1. What Broca (1861) described as aphemia, Wernicke (1874) called motor aphasia. Marie (1906) did not consider Broca's aphemia true aphasia. Pick (1913) labelled it expressive aphasia with agrammatism and Weisenburg \& McBride (1935) popularized "expressive aphasia" which still enjoys favor among many. The problem with the term "expressive" is that all aphasics have some "expressive" difficulties. Then came the "innovators" such as Henry Head (1926) whose distaste for his predecessors' diagrams resulted in a unique psycholinguistic classification which is difficult to apply to clinical cases. Broca's aphasia thus became "verbal aphasia". After Head, only Wepman (1951) used the same terminology extensively in the literature. Luria's (1964) physiological concepts led to "efferent motor" aphasia. Jacobson's (1964) linguistic approach used "contiguity" or "combination" disorders for this phenomenon and Osgood (1963) called it "encoding" disturbance. Bay (1964) like Marie (1906) considered "aphemia" different from aphasia and gave it the term "cortical dysarthria", a theoretical deviation from the consensus which considers these patients aphasic. Shuell's (1964) classification is highly individualistic and difficult to correlate with others. Her Group 3 "severe reduction of language" with "sensorimotor" disturbance corresponds best to Broca's aphasia.

More recent clinically and linguistically oriented classifications place 
an emphasis on the fluencynonfluency dichotomy in aphasia. Goodglass and Kaplan (1972) and many others recognized the clinical relevance of measuring fluency. They also advocate the retention of the classic eponym rather than using "motor" or "expressive" aphasia in order to avoid suggesting that speech output is normal in other forms of aphasia.

Much of the controversy about Broca's aphasia centers around the existence of comprehension deficit. These patients are characterized by relatively well-preserved comprehension and their major disability is in language output. However, if comprehension is examined extensively, it is found to be impaired to a certain extent, almost without exception. This prompted many investigators to emphasize that comprehension is an all pervasive feature of aphasia and the variable amount of motor difficulty at times labelled "cortical dysarthria", superimposed on aphasia results in the variation of the clinical picture called Broca's aphasia. Mohr (1975) claims that Broca's aphasia is rarely seen from the onset of a C.V.A. as a distinct entity but develops from global aphasia, by virtue of improving comprehension, or if it is present early after a stroke, it often evolves into a milder syndrome. Most clinicians agree, however, that motor aphasia, primarily expressive aphasia or Broca's aphasia, is an identifiable aphasic syndrome with hesitant, scant and paraphasic spontaneous speech, variably impaired repetition and naming, and relatively good comprehension. They read aloud poorly but reading comprehension is often good. Writing is affected similarly to speech.

2. Sensory aphasia as described by Wernicke (1874) in his famous paper, "Der Aphasische Symptomenkomplex" is recognized by everyone, even those wary of classifications such as Hughlings Jackson (1879). His hierarchial view of language dissolution includes "jargon" as a disturbance of expression but these recurrent utterances were more stereotypic than the profuse phonemic or semantic jargon of sen- sory aphasia. Marie (1906) claimed that sensory aphasia was the true aphasia and this is still championed by Bay (1964). Shuell (1964) was also impressed by the auditory disturbance as the sine qua non of aphasia. Curiously, her classification does not have a single group which could be identified unequivocally with sensory or Wernicke's aphasia. Head, like Wepman and Shuell after him, in order to avoid the inputoutput dichotomy and the notion of pure language defects, created novel. classifications deviating from the clinically obvious, and confusing generations of readers. Head's syntactic aphasia is not the same as Wepman's who called sensory aphasia "pragmatic" and the motor "syntactic"'. Jacobson's (1964) "similarity" or "selection" disorder encompasses a range of clinical disturbances such as "sensory", "semantic" and "acoustic amnestic' aphasia as he used Luria's (1964) terminology. According to him sensory aphasia is characterized linguistically by preserved syntactic units, and phonemic combinations although certain phonemic distinctions are lost. Osgood's (1963) decoding disturbance is in this category also.

Jargon aphasia is at times identified as a separate entity although most writers will classify it with Wernicke's or sensory aphasia. The fluent, profusely paraphasic speech may be usefully subdivided into semantic and neologistic jargon, depending on the degree of phonemic distortions or neologisms (the paraphasic and asemantic jargon of Alajouanine, 1956). These patients are often curiously unaware of their faulty communication and this is described as "anosognosia" for speech. Their speech is often under pressure, "logorrheic'". The variability of language production in Wernicke's aphasias induced some to split the symptom complex further. Huber et al., (1975) for instance, differentiates four varieties such as 1. predominantly semantic paraphasia, 2. semantic jargon, 3 . phonemic paraphasias, 4. phonemic jargon, although a qualitative basis for the discrimination is not provided.
Wernicke's aphasia as described by Goodglass and Kaplan (1972), features impaired comprehension and fluently articulated, but paraphasic speech. Repetition, naming or word-finding difficulty and impaired reading and writing are always present. Since various degrees of impairment are seen and the fringes of the entity are often illdefined and controversial, retention of the eponym seems useful to describe this clinically valid and common aphasic impairment.

3. Probably the largest group of aphasics have relatively little expressive or receptive difficulty. Their speech is fluent, at times very circumlocutory, occasionally paraphasic, and shows obvious word-finding difficulty. Their verbal paraphasias are semantic substitutions, rather than phonemic (literal) distortions. They have near normal comprehension and repetition but their naming is impaired. This is often called anomic or amnesic aphasia and this often appears de novo or it may be the end result of recovering from other syndromes, such as Wernicke's, "conduction", or the "transcortical aphasias".

Although Broca himself spoke about "verbal amnesia", this entity was not defined until Goldstein (1924) described amnesic aphasia as an impairment of "abstract attitude". Henry Head (1926) described nominal aphasia as a difficulty in naming but included impaired understanding of names as part of the disturbance, which is contrary to what clinicians usually find in this picture.

4. Another common aphasic group is universally called global aphasia because of the severity of involvement of both expressive and receptive functions. The patient does not communicate and what is said is often a stereotypic repetitive utterance, at times, an expletive without semantic value. At times these utterances are used quite fluently, with inflection and associated emotional expression. Comprehension seems almost entirely absent and even when one has the impression that the patient "looks comprehending", the expressive outlets are so limited that 
it cannot be tested. Similarly, repetition and naming are very poor. Recent studies of recovery indicate that quite a few global patients regain enough comprehension to be considered Broca's aphasics. There are a few patients, often elderly, with severe aphasia, who have fluent but mumbling speech, which may be mistaken for jargon, but the utterances are stereotypic lacking the phonemic variability of neologistic jargon aphasia.

There are aphasics who are more difficult to classify. A transitional group, having features of Broca's (good comprehension) and Wernicke's (good fluency) but having poor repetition and a great deal of phonemic paraphasias, was called conduction aphasia (Leitungsaphasie) by Wernicke (1874) on the basis of the theoretical consideration that conduction of sensory impulses to motor patterns is impaired. Many clinicians doubted the justification of separating this group from other sensory and motor impairment. Weisenburg and McBride (1935) claim that they have not seen a case which would show clearly the picture of conduction aphasia in contrast to Goldstein's description of "central" aphasia (1948) and those of Kleist (1916), Isserlin (1936) and many others who considered it an independent form. Delineation is possible on the basis of disturbed repetition which is out of proportion to the relatively fluent spontaneous or responsive speech and good comprehension.

The opposite clinical picture is echolalic aphasia when repetition is preserved out of proportion compared to the other language functions. These patients were subdivided by Goldstein (1948) into transcortical motor (T.C.M.) showing poor output but good comprehension and repetition; transcortical sensory (T.C.S.) characterized by poor comprehension but fluent speech and good repetition and mixed, featuring poor comprehension, poor output but good repetition similar to echolalia. The identity of these syndromes is defined by repetition and one has to test for it specifically. However, one only has to see a few T.C.M. cases to recognize the patient who says practically nothing spontaneously but comprehends everything and repeats amazingly well. Rubens (1975) has described this syndrome with infarction of the anterior cerebral artery. We have seen this localization also (supplemental speech area of Penfield). Isolation syndrome, also a recently described entity is exemplified by the patient who remains non-fluent and does not seem to be comprehending or attending to tasks but will repeat even longer phrases and complete sentences. One of these patients who had been observed to sing along with a radio and even learn songs released since the onset of her illness caused by $\mathrm{CO}$ poisoning (Geschwind, Quadfasel and Segarra, 1968), on autopsy had lesions surrounding but not directly involving the parasylvian "speech area". Transcortical (echolalic) sensory aphasia is characterized by fluent but often irrelevant speech. Good repetition and poor comprehension is most often seen in post-traumatic cases and it is often transient. Investigators in rehabilitation units do not see these patients as often as those in general hospitals. T.C.S. aphasia does not seem to occur frequently with strokes. Many classifications will acknowledge the existence of only those aphasic defects which tend to persist in time. This way some theoretically very interesting language disturbances remain unrecognized.

Semantic aphasia was described originally by Head and meant impaired word-meaning relationships and difficulty in formulating the goals of the speaker. The linguistic classification of Jacobson and Luria continued to use the term. Interestingly, in our mathematical taxonomy there is a group similar to but distinct from anomic aphasia by more paraphasias and comprehension difficulty which is not severely enough affected to group it with Wernicke's (or sensory) aphasia. It may be realistic to preserve the distinction between semantic and anomic aphasia, reserving the term anomic for the purer disturbance of wordfinding and naming and the semantic for mild impairment of comprehension associated with verbal paraphasias.

Modality specific aphasias are rare and seldom if ever "pure". "Cortical dysarthria" (aphemia), "verbal apraxia" (Johns and Darley, 1970 ) is rarely if ever without some associated disturbance of comprehension provided the appropriately difficult tests are used. Therefore, it should be considered aphasia rather than dysarthria. This has to be differentiated from the occasional anarthric patient by testing writing which is usually impaired in the aphasic but intact in anarthria. This entity is also called "subcortical motor aphasia", even though it is a nonaphasic disturbance related more to dysarthria. Transcortical motor aphasics may also appear to be mute but they will repeat well.

"Pure word deafness" is occasionally seen but most authors admit that their patients had some paraphasias and word-finding difficulty even though the comprehension deficit can be outstanding while everything else, including pure tone threshold is preserved. Interestingly, as Vignolo (1969) pointed out in his excellent review, these patients usually have "auditory agnosia" for nonverbal but meaningful sounds as well.

Modality specific anomia is controversial but an often recognized example is the difficulty naming fingers and discriminating right from left in the Gerstmann syndrome (1927). Although Benton (1961) pointed out that this cluster of symptoms including agraphia and acalculia is rarely pure and the components are often disturbed in aphasics, this does not detract from its usefulness in calling attention to the dominant parietal lobe.

Alexia without agraphia has been described with pathology by $\mathrm{De}$ jerine (1892) and repeatedly confirmed since. Alexia with agraphia is more common and it is often associated with mild anomic aphasia.

The discussion of apraxias and various visual or tactile agnosias and constructional apraxia will be omitted here for sake of convenience, not 


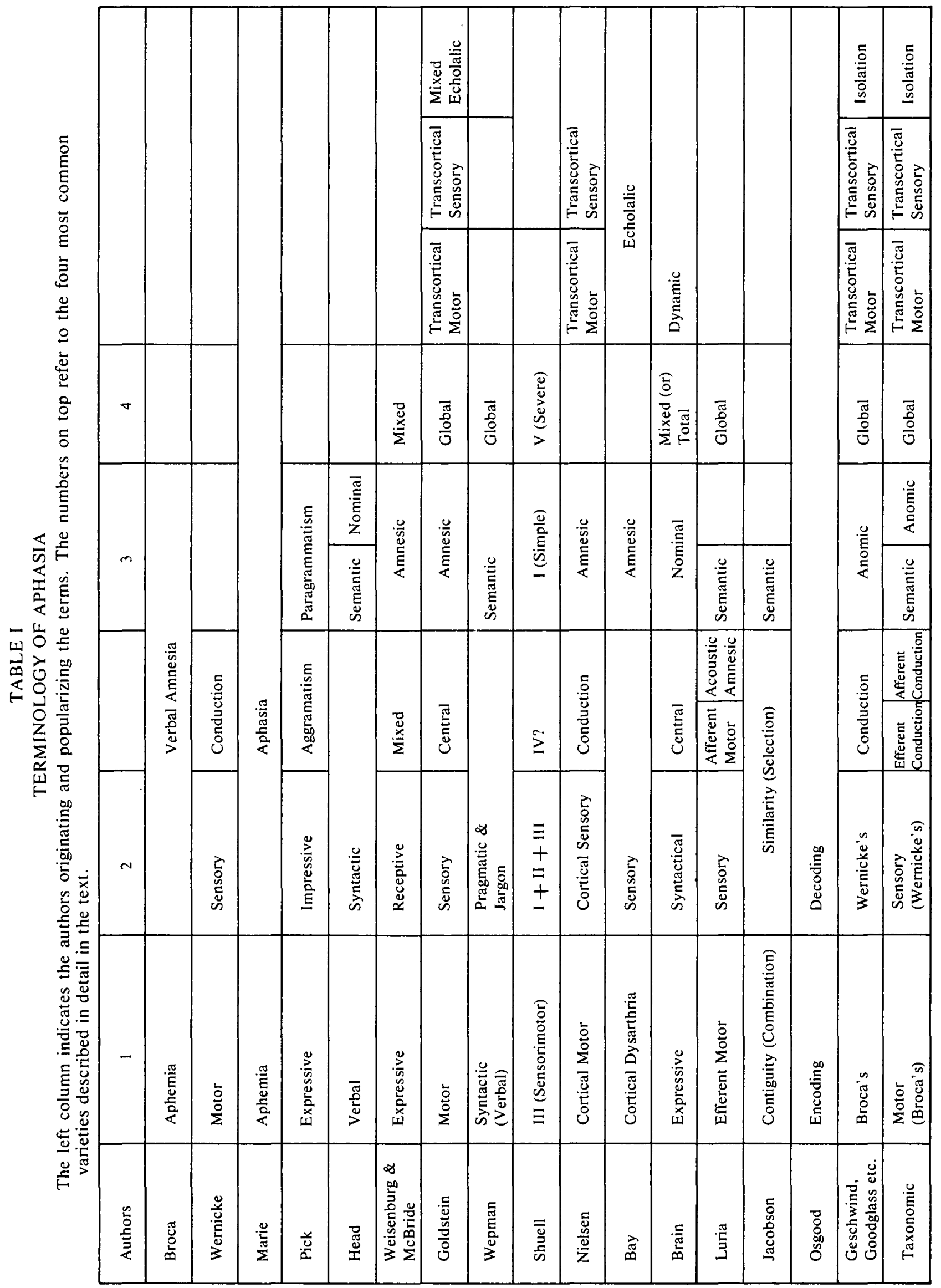


because they are unrelated to aphasia.

Even though aphasic disorders often need to be classified, clinicians are reluctant to define aphasic types according to measurable parameters. Most investigators are satisfied with impressions of unmeasured performance or established criteria on the basis of one, at the most two, parameters such as the severity or fluency-nonfluency scale. Recently attempts were made to define clinically recognizable aphasic groups according to the performance on certain tests (Vignolo, 1964; Kertesz, 1974). Beyond these intuitive classifications (taxonomies) a mathematical approach to classification became available to biologists and clinicians. Numerical taxonomy as it is called can provide objective clusters of aphasics on the basis of test scores, free from the constraints of previous classifications.

At the bottom of Table 1 , the 10 groups generated by numerical taxonomic methods (Kertesz and Phipps, 1976) on 142 stroke patients are labelled with due respect to current terminology and previous classifications. The major addition to the Goodglass, Kaplan, Geschwind classification is the splitting of conduction and anomic groups (labelling them efferent conduction, afferent conduction, and semantic and anomic aphasias respectively).

\section{REFERENCES}

ALAJOUANINE, T. et al. (1939). Le syndrome de desintegration phonetique dans Paphasie. Paris: Masson.
ALAJOUANINE, T. (1956). Verbal realization in aphasia. Brain 79, 1-28.

BAY, E. (1964). Principles of classification and their influence on our concepts of aphasia in Disorders of Language. London: Churchill, 122-142.

BENTON, A. (1961). The fiction of the "Gerstmann Syndrome". J. Neurol., Neurosurg. Psychiat. 24, 176-181.

BROCA, P. (1861). Remarques sur le siege de la faculte du langage articule, suivies d'une observations d'aphemie (perte de la parole). Bull. Soc. Anat. 36, 330-357.

DEJERINE, J. (1892). Contribution a l'étude anatomo-pathologique et clinique des differentes varietes de cecite verbale. C.R. Soc. Biol. (Paris) 4, 61-90.

GERSTMANN, J. (1927). Fingeragnosie und isolierte agraphie ein neues syndrom $\mathrm{Z}$. Qes. Neurol. U. Psychiat. 108, 152-177.

GESCHWIND, N., QUADFASEL, F. A. and SEGARRA, J. (1968). Isolation of the speech area Neuropsychologia 7, 327-340.

GOLDSTEIN, K. (1924). Das Wesen der amnestischen Aphasie. Schweiz. Arch. J. Neur. \& Psychiat. 15, 163-175.

GOLDSTEIN, K. (1948). Language \& language disturbances. New York: Grune \& Stratton.

GOODGLASS, H., KAPLAN, E. (1972). Assessment of aphasia and related disorders. Philadelphia: Lea \& Febiger.

HEAD, H. (1926). Aphasia and kindred disorders of speech. New York: Macmillan.

HUBER, W., STACHOWIAK, F. J., POECK, $\mathrm{K}$. and KERSCHENSTEINER, M. (1975). Die Wernicke's aphasie. J. Neurol. 210, 77-97.

ISSERLIN, M. (1936). Aphasie. in Handb. du Neurol. O. Bumke \& O. Foerster (eds.) Berlin, Springer 6, 627-806.

JACKSON, J. H. (1879). On affectations of speech from diseases of the brain. In Selected Writings, New York: Basic, 129-145, 1958.

JACOBSON, R. (1964). Towards a linguistic typology of aphasic impairments in Disorders of Language, London: Churchill, 21.42 .

JOHNS, D. F. and DARLEY, F. L. (1970). Phonemic variability in apraxia of speech. J. Speech and Hearing Res. 13, 556-583.
KERTESZ, A. and POOLE, E. (1974). The aphasia quotient. Canad. J. Neurol. Sci. I, 7-16.

KERTESZ, A. and PHIPPS. J. (1976). Numerical taxonomy of aphasia. Brain and Language (in press)

KLEIST, K. (1916). Uber Leitungsaphasie und grammatishe Storungen Monatschsr. $\mathrm{f}$. Psych. u. Neurol. 40, 118-121.

LURIA, A. (1964). Factors and forms of aphasia in Disorders of Language. London: Churchill.

MARIE, P. (1906). Revision de la question de l'aphasie: l'aphasie de 1861 a 1866: essai de critique historique sur la genere de la doctrine de Broca. Sem. Mid. Paris: 26, 565-571.

MOHR, J. P. (1975). Superficial and deep anterosuperior sylvian syndromes. Abstract, IV Pan American Congress of Neurology. Oct. 1975. Mexico City. pg. 7.

OSGOOD, C. E. and MIRON. M. S. (eds.) (1963). Approaches to the study of aphasia, Urbana Univ., Illinois Press.

PENFIELD, W. and ROBERTS, L. (1959). Speech and brain mechanisms. Princeton Univ. Press. Princeton, New Jewsey.

PICK, A. (1913). Die agrammatischen sprachstorungen. Berlin: Springer.

RUBENS, A. B. (1975). Aphasia with infarction in the territory of the anterior cerebral artery. Cortex XI, 239.

SCHUELL, H. (1964). Aphasia in adults: diagnosis, prognosis and treatment. Harper and Row.

VIGNOLO, L. A. (1964). Evaluation of aphasia and Language Rehabilitation: a retrospective exploratory study. Cortex I. 344-367.

VIGNOLO, L. A. (1969). Auditory agnosia: a review and report of recent evidence in contributions to clinical neuropsychology. Chicago: Aldine Publ. Co.

WEISENBURG, $T$, and McBRIDE, $K$. (1935). Aphasia. New York: Commonwealth Fund

WEPMAN, J. M. (1951). Recovery from aphasia, New York: Ronald.

WERNICKE, C. (1874). Der aphasische symptomenkomplex. Cohn \& Weigart. Breslau, in Boston Studies on the Philosophy of Science IV: 196, Dordrecht: Reidel. 